\title{
TU/e EmonONEN

\section{Pressure and temperature dependence of silicon doping of GaAs using Si2H6 in metalorganic chemical vapour deposition}

Citation for published version (APA):

Hageman, P. R., Croon, de, M. H. J. M., Reek, J. N. H., \& Giling, L. J. (1992). Pressure and temperature dependence of silicon doping of GaAs using Si2H6 in metalorganic chemical vapour deposition. Journal of Crystal Growth, 116(1-2), 169-177. https://doi.org/10.1016/0022-0248(92)90126-4

DOI:

10.1016/0022-0248(92)90126-4

Document status and date:

Published: 01/01/1992

Document Version:

Publisher's PDF, also known as Version of Record (includes final page, issue and volume numbers)

Please check the document version of this publication:

- A submitted manuscript is the version of the article upon submission and before peer-review. There can be important differences between the submitted version and the official published version of record. People interested in the research are advised to contact the author for the final version of the publication, or visit the $\mathrm{DOI}$ to the publisher's website.

- The final author version and the galley proof are versions of the publication after peer review.

- The final published version features the final layout of the paper including the volume, issue and page numbers.

Link to publication

\section{General rights}

Copyright and moral rights for the publications made accessible in the public portal are retained by the authors and/or other copyright owners and it is a condition of accessing publications that users recognise and abide by the legal requirements associated with these rights.

- Users may download and print one copy of any publication from the public portal for the purpose of private study or research.

- You may not further distribute the material or use it for any profit-making activity or commercial gain

- You may freely distribute the URL identifying the publication in the public portal.

If the publication is distributed under the terms of Article 25fa of the Dutch Copyright Act, indicated by the "Taverne" license above, please follow below link for the End User Agreement:

www.tue.nl/taverne

Take down policy

If you believe that this document breaches copyright please contact us at:

openaccess@tue.nl

providing details and we will investigate your claim. 


\title{
Pressure and temperature dependence of silicon doping of GaAs using $\mathrm{Si}_{2} \mathrm{H}_{6}$ in metalorganic chemical vapour deposition
}

\author{
P.R. Hageman, M.H.J.M. de Croon ', J.N.H. Reek and L.J. Giling \\ RIM, Department of Experimental Solid State Physics, Faculty of Science, University of Nijmegen, \\ Toernooiceld, 6525 ED Nijmegen, Netherlands
}

Received 4 August 1991

The doping of GaAs with disilane in a metalorganic chemical vapour deposition (MOCVD) process has been investigated at various input concentrations of disilane, total pressures and temperatures. The carrier concentration is linearly dependent on the input concentration of disilane. The temperature dependence of the incorporation process of silicon using disilane as a precursor changes as the total pressure varies. At a total pressure of 100 mbar the process is temperature independent in contrast to the behaviour at total pressures of 20 and 1000 mbar. So the doping process with disilane appears to depend on the total pressure. Using the concept of chemical boundary layer, the results are explained in terms of the different rate determining steps in the doping process as a function of different total pressures.

\section{Introduction}

Metalorganic chemical vapour deposition (MOCVD) has become one of the most important growth techniques of III $/ \mathrm{V}$ semiconductor materials. Many different devices can be manufactured employing MOCVD. Most of these device structures consist of one or more n-type layers. In MOCVD only a few elements are used for n-type doping of III/V semiconductor layers, viz. Te, S, Se and Si. Among these elements silicon can be employed for low $\left(n \approx 1 \times 10^{15}\right.$ $\mathrm{cm}^{-3}$ ) and high doping levels (up to $n \approx 1 \times 10^{18}$ $\mathrm{cm}^{-3}$ ), without exceptionally high compensation levels [1]. Moreover, it is possible to obtain abrupt doping profiles with silicon as a dopant because of its lack of memory effects [2], its low diffusion coefficient in GaAs and its low elemental vapour pressure [3].

In the early days only silane was used as dopant source for silicon in MOCVD [4,5]. The major

\footnotetext{
' Present address: Laboratorium voor Chemische Technologie, Technical University of Eindhoven, P.O. Box 513, Eindhoven, Netherlands.
}

disadvantage of silane is its temperature dependence of the incorporation process in GaAs [5-11] and other III/V materials. This effect can be as large as a $2 \%$ change in carrier concentration for a variation of $1^{\circ} \mathrm{C}$ for a growth temperature of $650^{\circ} \mathrm{C}[12]$. Therefore it is very difficult to obtain uniform doping profiles over a wafer if temperature gradients are present, even if they are small. Disilane as an alternative silicon dopant source for the doping of III $/ \mathrm{V}$ semiconductors was proposed by Kuech et al. [13]. It appeared that disilane does not lead to a temperature dependence of the incorporation process. It also has a higher doping efficiency than silane, at least in the temperature and pressure regimes used [1216]. However, more detailed studies of this process reveal that doping of GaAs with disilane also can be temperature dependent when different growth conditions are employed $[8,9,14,17]$.

In an earlier paper [9] we presented an analysis of the incorporation of silicon from disilane in $\mathrm{GaAs}$ at a total reactor pressure of 1 bar based on the concept of the chemical boundary layer $[18,19]$. This new study will treat the analysis in more detail and at various total reactor pressures 
in combination with new experimental data on the pressure and temperature dependence of the doping of GaAs with disilane.

\section{Experimental procedure}

In our experiments we investigated the temperature and pressure dependence of silicon incorporation in GaAs using disilane as a dopant. The study was carried out in a commercial, computer controlled MOCVD reactor [20] using trimethylgallium (TMG) and arsine $\left(\mathrm{AsH}_{3}\right)$ as source materials. As a dopant precursor $100 \mathrm{ppm}$ disilane $\left(\mathrm{Si}_{2} \mathrm{H}_{6}\right)$ in $\mathrm{N}_{2}$ was used. Hydrogen, purified by a Pd-diffusion cell, was used as carrier gas at a flow rate of $7 \mathrm{SLM}$. The pressure of the reactor is adjustable between 20 and 100 mbar; however, it is also possible to perform experiments at atmospheric pressure. The reactor cell has a rectangular cross-section and is heated by infra-red radiation.

All experiments were carried out with a ratio of $\mathrm{AsH}_{3}$ and TMG (V/III ratio) of 125. The growth temperature, determined by a thermocouple placed in the susceptor close to the substrate, varied between $550^{\circ}$ and $800^{\circ} \mathrm{C}$. Disilane was added to the reactor in mol fractions from $1 \times$ $10^{-10}$ to $4 \times 10^{-7}$. The GaAs growth rate varied, depending on the growth temperature and pressure in the reactor, from 1.4 to $2.3 \mu \mathrm{m} / \mathrm{h}$.

The GaAs substrates were all semi-insulating and chemo-mechanically polished on one side. All substrates used in this study were $(100) 2^{\circ}(110)$ oriented. The thickness of the grown layers was obtained by cleaving and staining, using an interference-contrast microscope or, if necessary, a scanning electron microscope (SEM). The samples were electrically characterized by Hall-Van der Pauw measurements performed at room temperature.

The material quality of the grown (undoped) epilayers was investigated by photoluminescence measurements. These measurements were performed at $4.5 \mathrm{~K}$, with the sample in He exchange gas. Optical excitation was provided by the 2.41 eV $(514.5 \mathrm{~nm})$ line from an $\mathrm{Ar}^{+}$laser with an excitation density of $5.3 \mathrm{~W} / \mathrm{cm}^{2}$. The lumines- cence was dispersed by a double monochromator fitted to a cooled photomultiplier tube with a S1 response.

\section{Results}

\subsection{Growth and characterization of undoped GaAs}

The growth rate of undoped GaAs is plotted versus the reciprocal temperature for three growth pressures $(20,100$ and 1000 mbar) in fig. 1. From this figure it appears that the growth rate of GaAs is virtually independent of the temperature at a pressure of 100 mbar. One has to conclude that at this pressure and in this temperature range $\left(600-700^{\circ} \mathrm{C}\right)$ the growth of GaAs is a diffusion limited process [21-23].

At the other total pressures ( 20 and $1000 \mathrm{mbar}$, fig. 1) the growth rate is only weakly dependent of the growth temperature. However, trends are still clear. At 20 mbar the apparent activation energy, $E_{\text {act }}$, for the growth process is now about $4 \mathrm{kcal} / \mathrm{mol}$ in the same temperature region. This points to the fact that the growth of GaAs at these conditions is determined by diffusion of the growth species to the substrate, coupled to the decomposition of trimethylgallium (TMG) $[23,24]$. The change of the apparent activation energy when going to lower pressures is caused by the lower residence times of the reactants in the

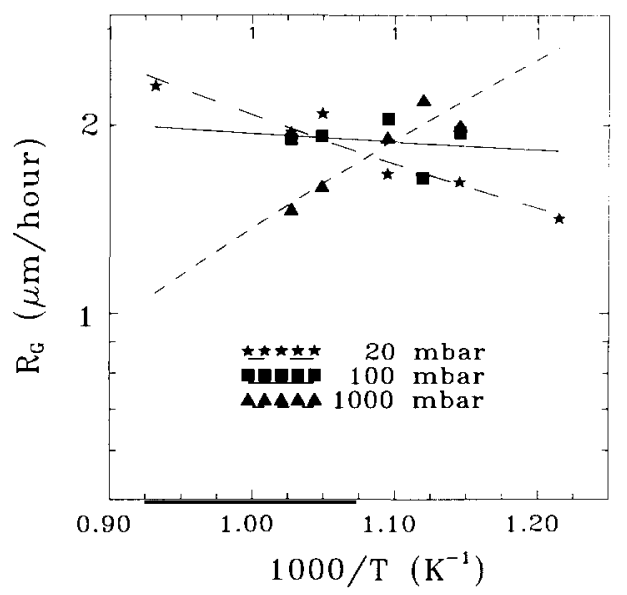

Fig. 1. Semi-log plot of the growth rate of GaAs in $\mu \mathrm{m} / \mathrm{h}$ versus $1000 / T$ at total pressures of 20,100 and 1000 mbar. 
reactor and lower collision frequencies compared to the situation at 100 mbar so that the kinetic control over the growth rate increases at this lower pressure [25]. At atmospheric pressure the $E_{\text {act }}$ of the growth process is $-4 \mathrm{kcal} / \mathrm{mol}$, so the growth process of GaAs seems to be determined by diffusion of the growth species to the substrate but now coupled to the high temperature desorption of the growth species from the substrate [21-23]. However, this result is not really reliable because of the influence of non developed flow profiles in the reactor at this pressure which will be discussed in section 4.3. So altering the total pressure (in this temperature region) at which the experiments are performed influences the rate determining step in the GaAs growth process.

In fig. 2, a photoluminescence (PL) spectrum is shown for an undoped GaAs sample grown at 20 mbar and at a temperature of $640^{\circ} \mathrm{C}$. This PL spectrum reveals the good quality and the low background doping level of the undoped GaAs epilayers. The well resolved and highly intense peak in the excitonic region, as compared to the also well resolved carbon acceptor peak, is an indication for a relative low carbon content and for a low residual impurity concentration of the sample. The largest peak in the excitonic region is the free excitonic transition peak and not a bound excitonic transition peak. This is a strong indication for a very low impurity content in the epilayer. A third indication for the good quality of the sample is the fact that higher excited states ( $n=2$ and $n=3$ ) from the free exciton peak are visible. Electrical characterization of these undoped layers was not possible because even epilayers up to $11 \mu \mathrm{m}$ thicknesses were fully depleted.

\subsection{Disilane doping of GaAs}

Fig. 3 shows the free carrier concentration $n$ $\left(=N_{\mathrm{D}}^{+}-N_{\mathrm{A}}^{-}\right)$in GaAs: Si versus the input mol

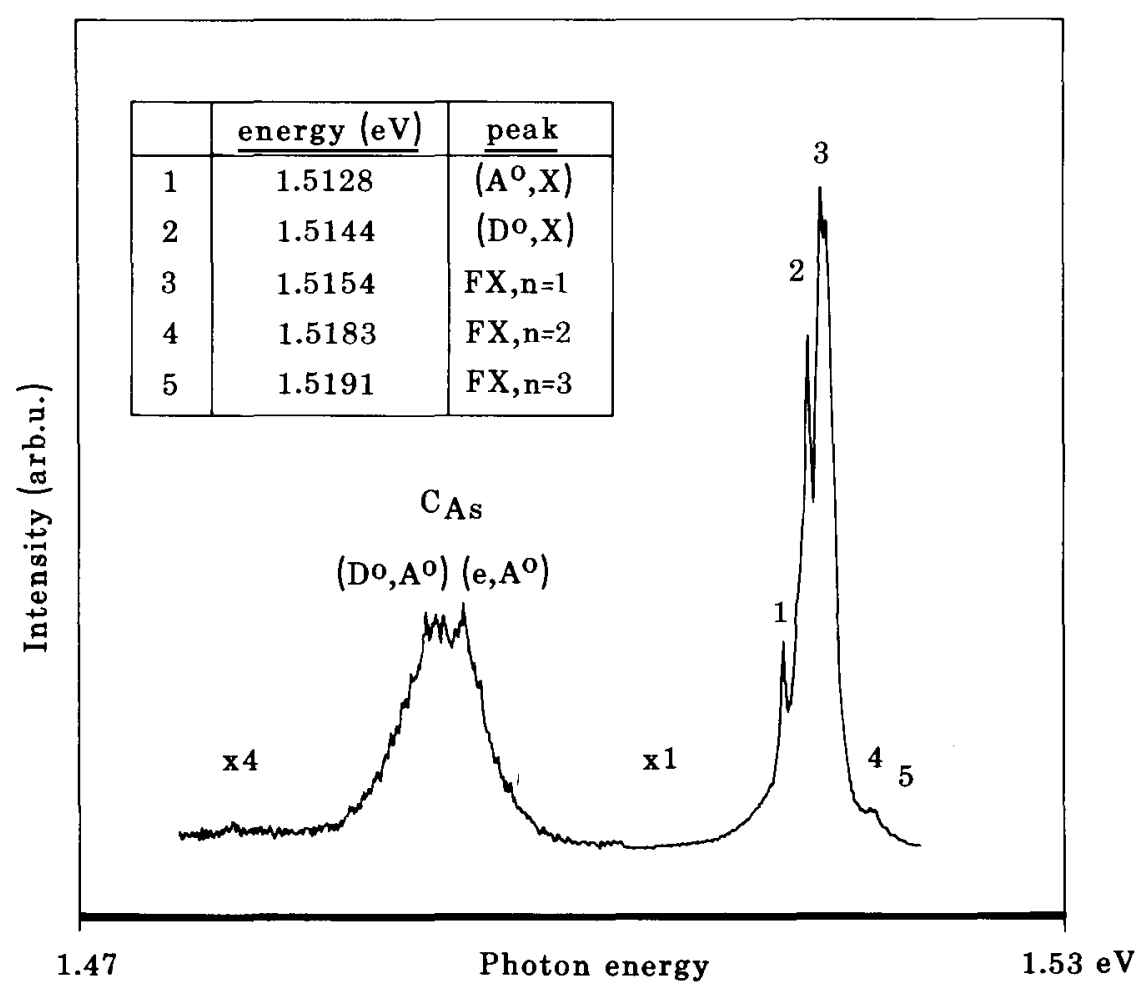

Fig. 2. Photoluminescence spectrum at $4 \mathrm{~K}$ of undoped GaAs grown at $640^{\circ} \mathrm{C}$ with a V/III ratio of 125 at $20 \mathrm{mbar}$. 


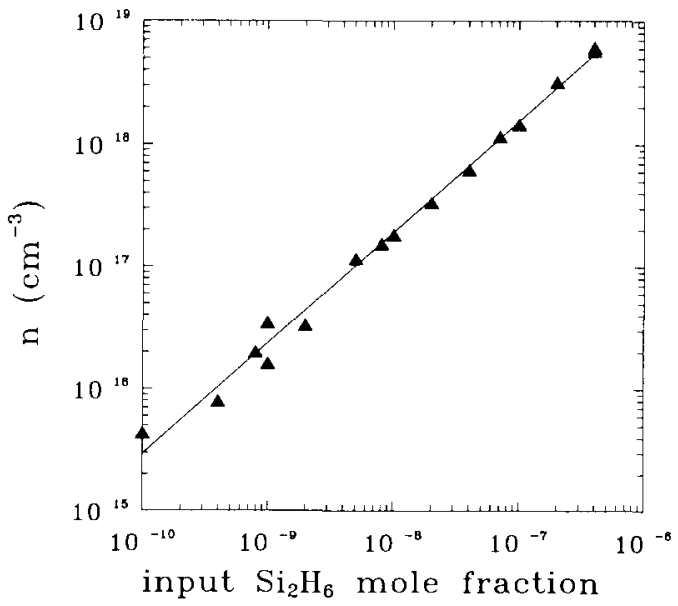

Fig. 3. Free carrier concentration $n\left(\mathrm{~cm}^{-3}\right)$ (in GaAs) plotted versus the input mol fraction of disilane. The growth was performed at $640^{\circ} \mathrm{C}$ with a $\mathrm{V} / \mathrm{III}$ ratio of 125 at $20 \mathrm{mbar}$.

fraction $\mathrm{Si}_{2} \mathrm{H}_{6}$ for a growth pressure of $20 \mathrm{mbar}$ as determined by room temperature Hall-Van der Pauw measurements. In this series of experiments the growth temperature $\left(T=640^{\circ} \mathrm{C}\right)$, the TMG and $\mathrm{AsH}_{3}$ partial pressures and the total pressure in the reactor $(20$ mbar) were kept constant.

In this log-log plot the carrier concentration increases linearly with respect to the disilane input mol fraction with a slope of 0.95 . Saturation of the carrier concentration is a common and undesired phenomenon in silicon doping of $\mathrm{GaAs}$ using $\mathrm{SiH}_{4}$ and $\mathrm{Si}_{2} \mathrm{H}_{6} \quad[1,7,11,12,14,16,26,27]$. However, no saturation is observed in the carrier concentration as a function of the input mol fraction $\mathrm{Si}_{2} \mathrm{H}_{6}$ in our measurements up till $n=$ $6.1 \times 10^{18} \mathrm{~cm}^{-3}$. Similar experiments at 100 and 1000 mbar have not been performed.

In fig. 4 the corresponding room temperature mobilities $(\mu)$ are plotted as a function of the free carrier concentration. As is visualized in this semi log plot the mobility is linearly dependent of the carrier concentration and no deviation from this linear dependence is observed. With the known values of the free carrier concentration and the mobilities a compensation ratio $\Theta$, defined as $\left(N_{\mathrm{A}}^{-} / N_{\mathrm{D}}^{+}\right)$, can be determined using the

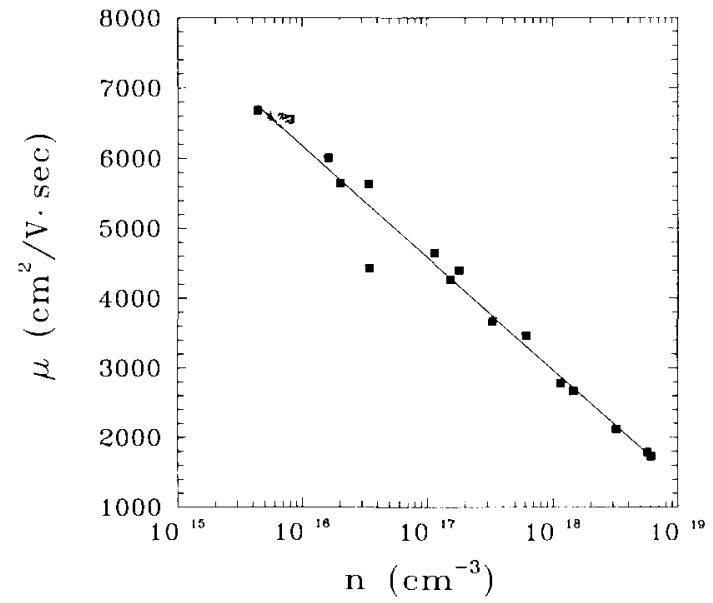

Fig. 4. Mobility $\mu$ plotted versus the free carrier concentration $n\left(\mathrm{~cm}^{-3}\right)$ for GaAs grown at at $640^{\circ} \mathrm{C}$ with a $\mathrm{V} / \mathrm{III}$ ratio of 125 at 20 mbar.

tables of Walukiewicz et al. [28]. The obtained values of $\Theta$ versus the free carrier concentration are plotted in fig. 5. A nearly constant value of about 0.3 is observed for $\Theta$ for all measured values of the free carrier concentration, demonstrating that no extra compensation occurs at the higher silicon concentrations. It is remarkable that the compensation ratio remains 0.3 , a normal value for relatively low doping levels. However, we obtained this value even at the highest carrier concentrations. In the literature one finds values of $\Theta$ as high as 0.7 at these doping levels [27].

In fig. 6 the silicon deposition rate $R_{\mathrm{Si}}$ is plotted as a function of the reciprocal tempera-

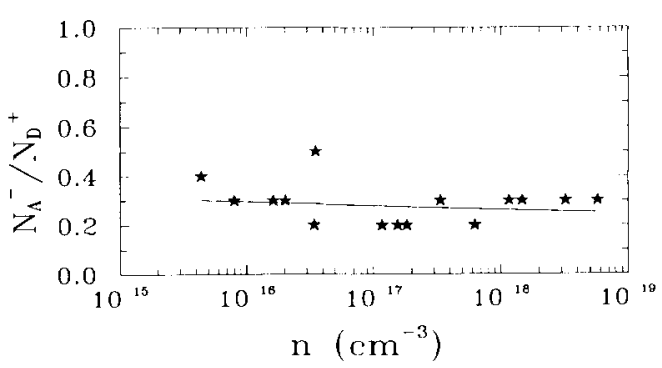

Fig. 5. Compensation ratio $\Theta$ of $\mathrm{GaAs}$ grown at $640^{\circ} \mathrm{C}$ with an V/III ratio of 125 at 20 mbar doped with disilane plotted versus the free carrier concentration $n\left(\mathrm{~cm}^{-3}\right)$. 


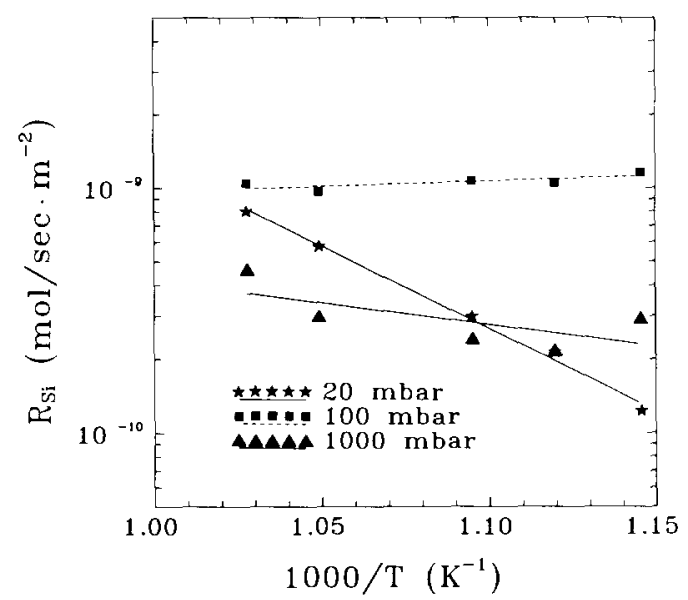

Fig. 6. Deposition rate of silicon $R_{\mathrm{Si}}$ in $\mathrm{mol} / \mathrm{s} \cdot \mathrm{m}^{-2}$ as function of $1000 / T$ for 3 different total pressures using $\Theta=0.3$.

ture at various total reactor pressures. This deposition rate is defined as:

$R_{\mathrm{Si}}=N_{\mathrm{Si}} M_{\mathrm{GaAs}} R_{\mathrm{GaAs}} / N_{\mathrm{Av}} \rho_{\mathrm{GaAs}}\left(\mathrm{mol} / \mathrm{m}^{2} \cdot \mathrm{s}\right)$,

in which $N_{\mathrm{Si}}$ equals the total incorporated silicon concentration, $M_{\mathrm{GaAs}}$ the molecular weight of GaAs and $R_{\text {GaAs }}$ the growth rate of GaAs in $\mathrm{mol} / \mathrm{m}^{2} \cdot \mathrm{s} . N_{\mathrm{Av}}$ is Avogadro's constant and $\rho_{\mathrm{GaAs}}$ is the density of GaAs.

Using the free carrier concentration as determined by Hall-Van der Pauw measurements and the corresponding compensation ratio, one can derive the following relation between the free carrier concentration and the incorporated silicon concentration [28]:

$N_{\mathrm{Si}}=\left(\frac{1+\Theta}{1-\Theta}\right) n$,

in which $n$ is the free carrier concentration (Hall-Van der Pauw) and $\Theta$ is the compensation ratio. In our experiments $\Theta$ nearly has a constant value of 0.3 . So eq. (1) becomes now:

$R_{\mathrm{Si}}=1.86 n M_{\mathrm{Ga} \Lambda s} R_{\mathrm{GaAs}} / N_{\mathrm{Av}} \rho_{\mathrm{GaAs}}\left(\mathrm{mol} / \mathrm{m}^{2} \cdot \mathrm{s}\right)$.

Using the silicon deposition rate $R_{\mathrm{Si}}$ (eq. (3)) instead of the normally used quantity $n$ (free carrier concentration) has the advantage of making the silicon incorporation process independent of the GaAs growth process. So in this manner the determined activation energy (calculated from fig. 6) more likely is the activation energy of the doping process alone and is not masked by the combination of the doping process and the deposition of GaAs.

Fig. 6 shows that at a total pressure in the reactor of 20 mbar the silicon doping process of GaAs using $\mathrm{Si}_{2} \mathrm{H}_{6}$ as a dopant source has an Arrhenius type of behaviour with an apparent activation energy, $E_{\text {act }}$, of $32 \mathrm{kcal} / \mathrm{mol}$. In contrast to this, a nearly temperature independent behaviour is observed for a total pressure of 100 mbar $\left(E_{\mathrm{act}}=-2 \mathrm{kcal} / \mathrm{mol}\right)$. At a pressure of 1000 mbar, however, the process again is temperature dependent with an $E_{\text {act }}$ of $9.5 \mathrm{kcal} / \mathrm{mol}$. Note, however, that the same value for the compensation ratio $(=0.3)$ as for the situation at 20 mbar has been used for the calculation of the positions of the experimental points in this figure. Experimentally it appears that at these higher pressures the compensation ratio only slightly differs from the situation at $20 \mathrm{mbar}$. In the log-log plot of fig. 6 this variation is hardly noticeable.

\section{Discussion}

For the doping of GaAs with $\mathrm{Si}_{2} \mathrm{H}_{6}$ as a dopant source, one has to consider the following chemical equations:

$$
\begin{aligned}
& \mathrm{SiH}_{4} \stackrel{k_{1}}{\longrightarrow} \mathrm{SiH}_{2}+\mathrm{H}_{2}, \\
& \mathrm{SiH}_{2}+\mathrm{H}_{2} \stackrel{k_{2}}{\longrightarrow} \mathrm{SiH}_{4}, \\
& \mathrm{Si}_{2} \mathrm{H}_{6} \stackrel{k_{3}}{\longrightarrow} \mathrm{SiH}_{4}+\mathrm{SiH}_{2}, \\
& \mathrm{SiH}_{4}+\mathrm{SiH}_{2} \stackrel{k_{4}}{\longrightarrow} \mathrm{Si}_{2} \mathrm{H}_{6}, \\
& \mathrm{SiH}_{2} \rightarrow \text { incorporation. }
\end{aligned}
$$

At forehand one can state that the decomposition of $\mathrm{SiH}_{4}$ (reaction (I)) and of $\mathrm{Si}_{2} \mathrm{H}_{6}$ (reaction (III)) are highly activated reactions with activation energies of about $50 \mathrm{kcal} / \mathrm{mol}[29,30]$. Although both decomposition reactions have about the same activation energy, reaction (III) is much 
faster than reaction (1) because of a higher preexponential factor in the rate equation $[29,30]$.

For the discussion of the experimental results, we assume that the completely saturated molecules $\mathrm{SiH}_{4}$ and $\mathrm{Si}_{2} \mathrm{H}_{6}$ have a sticking coefficient of about zero at the GaAs surface, as these molecules only can adsorb physically at the surface, whereas the radical $\mathrm{SiH}_{2}$ has a sticking coefficient of about 1 . Due to the strong $\mathrm{Si}-\mathrm{As}$ and $\mathrm{Si}-\mathrm{Ga}$ bonds, desorption of $\mathrm{SiH}_{2}$ from the growth surface is unlikely to happen in the temperature range of the experiments. This implies that silylene is the species that will be incorporated and not silane or disilane. The rate of reaction (IV) is under almost every growth condition negligible because of the very low concentration of the silicon containing species (e.g. $\mathrm{SiH}_{2}$ and $\mathrm{SiH}_{4}$ ) in the gas mixture. Although in this way the system has been simplified, it is still very complicated to derive the exact rate equation for the incorporation of silicon in GaAs using $\mathrm{Si}_{2} \mathrm{H}_{6}$ as a precursor. But a qualitative description, which will satisfy for explaining the results of most growth experiments, will be given below.

Using the concept of the chemical boundary layer $[18,19]$ we can calculate for reactions (I), (II) and (III) the thicknesses of their respective chemical boundary layers $\delta_{1}, \delta_{2}$ and $\delta_{3}$, using the following equation $[18,19,24]$ :

$\delta \approx \frac{(1+\beta)\left(T_{\mathrm{s}} / T_{0}\right)^{1+\beta}}{\left(T_{\mathrm{s}} / T_{0}\right)^{-\beta}}-\frac{R_{\mathrm{G}} T_{\mathrm{s}}}{E_{\mathrm{acl}, i}} \delta_{T}$,

in which $T_{\mathrm{s}}$ is the susceptor temperature, $T_{0}$ is the temperature of the top of the reactor, $\beta$ equals the temperature dependence of the thermal conductivity of the carrier gas $(\approx 0.7), R_{\mathrm{G}}$ is the gas constant, $\delta_{T}$ is the width of the temperature boundary layer which is in our case the height of the reaction $(3 \mathrm{~cm})$ and $E_{\mathrm{act}, i}(\mathrm{kcal} / \mathrm{mol})$ is the activation energy of the particular reaction. This equation can be simplified to:

$\delta \approx \frac{4}{E_{\mathrm{acc}, i}} \delta_{T}(\mathrm{kcal} / \mathrm{mol})$.

The simplification (5) is only valid at a susceptor temperature of about $1000 \mathrm{~K}$ and a reasonably high $E_{\text {act }}[18]$.

Due to the fact that the activation energies of reactions (I) and (III) are about equal, it is obvious from eq. (2) that $\delta_{1}=\delta_{3}$ (about $2.5 \mathrm{~mm}$ ). Reaction (II) has a very low activation energy of about $3.5 \mathrm{kcal} / \mathrm{mol}$ [29], which leads to such a great value of $\delta_{2}$ that this safely can be set equal to the height of the reactor.

\subsection{Disilane doping of GaAs at $100 \mathrm{mbar}$}

The deposition rate of silicon $\left(R_{\mathrm{Si}}\right)$ consists of a kinetically determined $\left(R_{\mathrm{K}}\right)$ and a diffusionally $\left(R_{\mathrm{D}}\right)$ determined part. Depending on the conditions (e.g. pressure, temperature, type of carriergas, etc.) one of these fluxes will dominate. In an approximated form the deposition rate of silicon, in this example ex $\mathrm{Si}_{2} \mathrm{H}_{6}$, can be expressed as:

$\frac{1}{R_{\mathrm{Si}}}=\frac{1}{R_{\mathrm{D}}}+\frac{1}{R_{\mathrm{K}}}$.

Here $R_{\mathrm{D}}$ equals the completely diffusionally limited deposition rate of silicon through the bulk of the gas phase, $R_{\mathrm{D}}=(D / h) C_{0}$, while $R_{\mathrm{K}}$ is the completely kinetically controlled deposition rate in the boundary layer, $R_{\mathrm{K}}=k \delta C_{0}$. In the expressions $D$ is the binary diffusion constant, $h$ the height of the reactor, $C_{0}$ the input concentration and $\delta$ the thickness of the chemical boundary layer. This leads to the following expression for the silicon deposition rate:

$R_{\mathrm{Si}}=\frac{k C_{0} \delta D / h}{D / h+k \delta}$

Here we have used already the concept of the chemical boundary layer, which implies that we have to divide the reactor into two parts, i.e. the chemical boundary layer itself and the bulk of the gas phase. A $N_{\mathrm{CVD}}$ number can be introduced for both the chemical boundary layer and the bulk gas phase ${ }^{\# 1}$. This dimensionless number is de-

\footnotetext{
Instead of this $N_{\text {( VD }}$ number, sometimes a Nusselt number has been used. This dimensionless number is defined as the ratio between the diffusional flux and the chemical reaction flux. A more correct name for this number is Damköhler II.
} 
fined as the ratio between the chemical reaction flux and the diffusional flux, i.e. it determines the relative magnitude of both parallel fluxes mentioned in eq. (6).

We now can calculate $N_{C V D}$ for the case of doping with $\mathrm{Si}_{2} \mathrm{H}_{6}$. From calculations of the diffusional flux of $\mathrm{Si}_{2} \mathrm{H}_{6}$ through the bulk gas phase $\left((D / h) C_{0}\right)$ coupled to the decomposition in the boundary layer $\left(k C_{0} \delta\right)$ (at a temperature of about $1000 \mathrm{~K}$ and at a total pressure in the reactor of 100 mbar), using the known values of $D_{300}$ and $k_{1000}[29,30]$, it follows that under these conditions the $N_{\mathrm{CVD}}$ number, $k_{1000} \delta /\left(D_{300} / h\right)$, is larger than 1. This points to the fact that the decomposition of disilane is fully controlled by diffusion from the bulk gas phase. Thus the doping process at 100 mbar total pressure will be completely limited by the diffusion of $\mathrm{Si}_{2} \mathrm{H}_{6}$ through the bulk of the gase phase. This favourably coincides with the results of the performed experiments and also with literature data $[8,9,12-14]$.

When we calculate the $N_{C V D}$ number for the chemical boundary layer for the decomposition of $\mathrm{Si}_{2} \mathrm{H}_{6}$ and the diffusion of $\mathrm{Si}_{2} \mathrm{H}_{6}$ through this layer, we arrive at a value in the order of 1 . For this case

$N_{\mathrm{CVD}}=\frac{k_{1000} \delta C_{0}}{C_{0} D_{1000} / \delta}=\frac{k_{1000} \delta^{2}}{D_{100 \%}}$.

This implies that $\mathrm{Si}_{2} \mathrm{H}_{6}$ decomposition and diffusion in the boundary layer at this pressure are equally important, so that the decomposition takes place about everywhere in the boundary layer with the same reaction rate. This decomposition leads to the production of the radical species $\mathrm{SiH}_{2}$. It is possible to calculate the amount of $\mathrm{SiH}_{2}$ produced in the boundary layer which will be able to reach the growing surface. Because of the fast reaction (II), the diffusion length of the $\mathrm{SiH}_{2}$ species is given by [24]:

$$
\sqrt{D_{\mathrm{SiH}_{2}} / k_{2} P_{\mathrm{H}_{2}}} \text {, }
$$

in which $D_{\mathrm{SiH}_{2}}$ is the binary diffusion constant of $\mathrm{SiH}_{2}$ in $\mathrm{H}_{2}$ and $k_{2}$ is the reaction constant of the reaction of $\mathrm{SiH}_{2}$ with $\mathrm{H}_{2}$ (reaction (II)) both at $1000 \mathrm{~K}$. For a total pressure of $100 \mathrm{mbar}$ and a temperature of about $1000 \mathrm{~K}$, this length is calculated to be about $3 \mathrm{~mm}$, which is larger than the width of the boundary layer $\delta_{3}$, meaning that most of the $\mathrm{SiH}_{2}$ produced in this layer will actually reach the growing surface and will be incorporated.

\subsection{Disilane doping of GaAs at 20 mbar}

At this relative low pressure, the diffusional fluxes will strongly increase compared to the situation at 100 mbar total pressure, because of the inverse pressure dependence of the binary diffusion constants. At the same time, the decomposition rate constant will decrease because of its total pressure dependence [30]. The calculated $N_{\text {CVD }}$ numbers in bulk and chemical boundary layer now appear to be both of order 1 . So the production of $\mathrm{SiH}_{2}$ species in this case will be determined both by diffusion and by kinetics. This coincides with the results given in fig. 6 and also with literature data [14]. The value of the experimentally determined apparent activation energy of $32 \mathrm{kcal} / \mathrm{mol}$ can be compared to the theoretical one as obtained from eq. (7) using

$D=D_{0}\left(T / T_{0}\right)^{1.7}$,

$k=A T^{\beta} \exp \left(-E_{\text {acc }} / R T\right)$,

with $E_{\text {act }}=51 \mathrm{kcal} / \mathrm{mol}$ [30]. This exercise gives a value of $38 \mathrm{kcal} / \mathrm{mol}$, which is equal to the measured value of $32 \mathrm{kcal} / \mathrm{mol}$ within the uncertainty limits of the experiments.

\subsection{Disilane doping of GaAs at 1000 mbar}

In this situation the total pressure is ten times as high as in the case of the situation of 100 mbar. This leads to smaller binary diffusion constants and higher decomposition rate constants [31] and thus to $N_{\text {CVD }}$ numbers which are larger than one both in the bulk and in the chemical boundary layer. One may deduce from this that at the top of the chemical boundary layer all $\mathrm{Si}_{2} \mathrm{H}_{6}$ will be decomposed into $\mathrm{SiH}_{4}$ and $\mathrm{SiH}_{2}$ and that this reaction is completely bulk gas phase diffusion limited.

Due to the fact that the total pressure is a factor of ten higher than the situation at 100 
mbar, also the concentration of $\mathrm{H}_{2}$ is ten times larger. This has considerable influence on reaction (II), i.e., it causes a large increase of the production of $\mathrm{SiH}_{4}$. A consequence is that the diffusion length of $\mathrm{SiH}_{2}$ (eq. (3)) becomes smaller than the width of the chemical boundary layer $\delta_{3}$. So inside this layer all $\mathrm{SiH}_{2}$ will, in practice, have reacted to $\mathrm{SiH}_{4}$, except for the fraction that is determined by the $\mathrm{SiH}_{4} \rightleftharpoons \mathrm{SiH}_{2}+\mathrm{H}_{2}$ equilibrium. This fraction will be very low due to the high concentration of $\mathrm{H}_{2}$.

Because of the equilibrium, the silane concentration will remain almost constant in the boundary layer. So at 1000 mbar, doping with $\mathrm{Si}_{2} \mathrm{H}_{6}$ effectively appears to be doping with $\mathrm{SiH}_{4}$. Therefore an activation energy of about 40-50 $\mathrm{kcal} / \mathrm{mol}$ is to be expected. In a reactor with fully developed flow and temperature profiles, we indeed found an activation energy of $45 \mathrm{kcal} / \mathrm{mol}$ [9]. However, the results presented in this paper give an activation energy of only $9.5 \mathrm{kcal} / \mathrm{mol}$. The large difference between these two values can be explained by taking into account the flow profiles at 1000 mbar in this reactor which is build for low pressures. Calculations reveal that, at $1000 \mathrm{mbar}$, in this relatively high cell $(3 \mathrm{~cm})$, memory cells and spiral rolls are present due to the high Grashof $(\approx 2100)$ and Raleigh numbers $(\approx 3000)$ [32], whereas fully developed laminar flows are present at 100 and 20 mbar in the same reactor. As the theory of chemical boundary layer only works well in fully developed flow profiles, as was shown in an earlier paper [9], we only can rely on the experimental results obtained in this work at 20 and 100 mbar. For atmospheric pressure data we refer to the data obtained in our earlier work [9].

The combined result is that the kinetics of the doping process of $\mathrm{Si}_{2} \mathrm{H}_{6}$ strongly depends on the total pressure and that consequently the apparent activation energy changes according to the step that determines the silicon deposition rate.

\section{Conclusion}

The doping of GaAs using disilane as a doping source was studied at different temperatures and total pressures. The incorporation of silicon from $\mathrm{Si}_{2} \mathrm{H}_{6}$ in GaAs is almost linearly dependent on the input concentration of disilane in the range from $4 \times 10^{1.5}$ up to $6.1 \times 10^{18} \mathrm{~cm}^{-3}$. No extra compensation due to the amphoteric behaviour of silicon in GaAs is observed, even not in the samples with the highest silicon concentrations. By applying different total pressures we investigated the pressure dependence of the doping process. At 100 mbar no temperature effect is found. The doping process is completely bulk gas phase diffusion controlled with an activation energy of $-2 \mathrm{kcal} / \mathrm{mol}$. This is in contrast to the experiments at 20 and $1000 \mathrm{mbar}$ where activation energies of 32 and $45 \mathrm{kcal} / \mathrm{mol}$ are measured. At the lowest total pressure the decomposition of $\mathrm{Si}_{2} \mathrm{H}_{6}$ almost completely determines the silicon deposition process with a small contribution of bulk diffusion. At 1000 mbar the decomposition of $\mathrm{SiH}_{4}$ instead of $\mathrm{Si}_{2} \mathrm{H}_{6}$ determines the silicon incorporation process.

So in conclusion $\mathrm{Si}_{2} \mathrm{H}_{6}$ is a good n-type dopant which can be used in a wide doping range, from $10^{15}$ to $10^{19} \mathrm{~cm}^{-3}$, without exceptionally high compensation ratios. To avoid differences in doping levels due to temperature gradients over the wafer, one should grow at total pressure of about 100 mbar.

\section{Acknowledgments}

The authors are greatly indebted to S.M. Olsthoorn for performing and discussing the photoluminescence measurements and to G. Bauhuis for performing the electrical characterization of the samples. This work was financed by NOVEM, Project No. 41.220-003.1.

\section{References}

[1] R. Venkatasubramanian, K. Patel and S.K. Gandhi, J. Crystal Growth 94 (1989) 34

[2] J.S. Roberts, N.J. Mason and M. Robertson, J. Crystal Growth 68 (1984) 422.

[3] R. Sankaran, J. Crystal Growth 50 (1980) 859.

[4] J.-P. Hallais, Acta Electron. 21 (1978) 129

[5] S.J. Bass, J. Crystal Growth 47 (1979) 613. 
[6] A.M. Beers and J. Bloem, Appl. Phys. Letters 41 (1982) 153.

[7] E. Veuhoff, T.F. Kuech and B.S. Meyerson, J. Electrochem. Soc. 132 (1985) 1958.

[8] H.K. Moffat, T.F. Kuech, K.F. Jensen and P.-J. Wang, J. Crystal Growth 93 (1988) 594.

[9] P.R. Hageman, X. Tang, M.H.J.M. de Croon and L.J. Giling, J. Crystal Growth 98 (1989) 249.

[10] J.P. Duchemin, M. Bonnet, F. Koelsch and D. Huyghe, J. Electrochem. Soc. 126 (1979) 1134.

[11] M. Druminski, H.-D. Wolf and K.-H. Zschauer, J. Crystal Growth 57 (1982) 318.

[12] T.F. Kuech, E. Veuhoff and B.S. Meyerson, J. Crystal Growth 68 (1984) 48.

[13] T.F.Kuech, B.S. Meyerson and E. Veuhoff, Appl. Phys. Letters 44 (1984) 986.

[14] M. Shimazu, K. Kamon, K. Kimura, M. Mashita, M. Mihara and M. Ishii, J. Crystal Growth 83 (1987) 327.

[15] H. Sakaguchi, R. Suzuki and T. Meguro, J. Crystal Growth 93 (1988) 602.

[16] N. Furuhata, K. Kakimoto, M. Yoshida and T. Kamejima, J. Appl. Phys. 64 (1988) 4692.

[17] T.F. Kuech, M.A. Tischler, P. Potemski, F. Cardone and G. Scilla, J. Crystal Growth 98 (1989) 174.

[18] M.H.J.M. de Croon and L.J. Giling, J. Electrochem. Soc. 137 (1990) 2867.

[19] M.H.J.M. de Croon and L.J. Giling, J. Electrochem. Soc. 137 (1990) 3606.
[20] D. Schmitz, G. Strauch, J. Knauf, H. Jürgensen and M. Heyen, J. Crystal Growth 93 (1988) 312.

[21] W.G.J.H.M. van Sark, M.H.J.M. de Croon, G. Janssen and L.J. Giling, Semicond. Sci. Technol. 5 (1990) 36.

[22] W.G.J.H.M. van Sark, M.H.J.M. de Croon, G.J.H.M. Janssen and L.J. Giling, Semicond. Sci. Technol. 5 (1990) 291.

[23] D.H. Reep and S.K. Ghandhi, J. Electrochem. Soc. 130 (1983) 675.

[24] M.H.J.M. de Croon and L.J. Giling, Progr. Crystal Growth Characterization 19 (1989) 125.

[25] M. Tirtowidjojo and R. Pollard, J. Crystal Growth 98 (1989) 420.

[26] T. Lideikis and G. Treideris, J. Crystal Growth 96 (1989) 790.

[27] X. Tang, H.G.M. Lochs, P.R. Hageman, M.H.J.M. de Croon, L.J. Giling and A.J. Bons, J. Crystal Growth 98 (1989) 827.

[28] W. Walukiewicz, L. Lagowski, L. Jastrebski, M. Lichtensteiger and H.C. Gatos, J. Appl. Phys. 50 (1979) 899.

[29] H.K. Moffat and K.F. Jensen, J. Electrochem. Soc. 135 (1988) 459.

[30] K.F. Roenigk, K.F. Jensen and R.W. Carr, J. Phys. Chem. 91 (1987) 5732.

[31] K.F. Roenigk, PhD Thesis, University of Minnesota (1987).

[32] E.P. Visser, C.R. Kleijn, C.A.M. Govers, C.J. Hoogendoorn and L.J. Giling, J. Crystal Growth 94 (1989) 929. 